\title{
DERECHOS HUMANOS, LIBERTAD Y FACTICIDAD: UNA LECTURA ALTERNATIVA DESDE EL PENSAMIENTO SARTRIANO
}

\author{
HUMAN RIGHTS, FREEDOM AND FACTICITY: AN ALTERNATIVE READING \\ FROM SARTREAN THOUGHT
}

\begin{abstract}
ENÁN ARRIETA BURGOS
Profesor de la Escuela de Derecho y Ciencias Políticas de la Universidad Pontificia Bolivariana, Medellín (Colombia). Abogado, especialista en Derecho Procesal y doctorando en Filosofía en esta Universidad. Este artículo es resultado de los proyectos de investigación "Del juzgar al otro: ensayo desde la mirada sartriana" y "Pensar en y contra Sartre: crítica de la concepción dialéctico materialista de la libertad humana desde el existencialismo fenomenológico de Jean-Paul Sartre" (investigación doctoral), aprobados y financiados por el Centro de Investigación para el Desarrollo y la Innovación (CIDI/UPB).
\end{abstract}

enan.arrieta@upb.edu.co

\begin{abstract}
RESUMO
O discurso dos direitos humanos tem servido para legitimar práticas de dominação e resistência. Críticos e ativistas de direitos humanos concordam sobre a necessidade de problematizar a sua fundamentação teórica. Bem, a partir do pensamento de Jean-Paul Sartre, este artigo tem o objetivo de estabelecer as bases de uma nova concepção de direitos humanos. Para este fim, alguns mal-entendidos relacionados com a visão de Sartre dos direitos humanos são apagadas, uma leitura crítica da compreensão padrão desses direitos é feito e as orientações para uma proposta alternativa, baseado no reconhecimento da liberdade e da factualidade delineado homem na situação.
\end{abstract}

Palavras-chave: direitos humanos; liberdade, factualidade; Jean-Paul Sartre, teoria crítica.

\section{RESUMEN}

El discurso de los derechos humanos ha servido para legitimar prácticas de dominación y resistencia. Críticos y defensores de los derechos humanos coinciden en la necesidad de problematizar su fundamento teórico. Pues bien, a partir del pensamiento de Jean-Paul Sartre, este artículo pretende sentar las bases de una nueva concepción de los derechos humanos. Con esta finalidad, se despejan algunos malos entendidos relacionados con la visión sartriana de los derechos humanos, se realiza una lectura crítica de la concepción estándar de estos derechos y se esbozan los lineamientos de una propuesta alternativa fundada en el reconocimiento de la libertad y la facticidad del hombre en situación.

Palabras clave: derechos humanos; libertad; facticidad; Jean-Paul Sartre, teoría crítica.

\section{SUMARIO}

INTRODUCCIÓN; 1. SARTRE Y LOS DERECHOS HUMANOS: DESPEJANDO ALGUNOS (NO POCOS) MALOS ENTENDIDOS; 2. LOS DERECHOS HUMANOS EN CUESTIÓN; 2.1. ¿El ser humano y la humanidad?; 2.2. El fundamento místico de los derechos humanos; 2.3. La moral de los derechos humanos; 2.4. La indigna dignidad humana; 2.5. La violencia de los derechos humanos; 3. DERECHOS HUMANOS, LIBERTAD Y FACTICIDAD; 3.1. Los derechos humanos: un derecho de provisión; 3.2. El llamado de los derechos humanos; 3.3. Responsabilidad y compromiso; CONCLUSIÓN; REFERENCIAS. 


\title{
INTRODUCCIÓN
}

\begin{abstract}
En cualquier caso, el mundo parece feo, malo y sin esperanza. Eso es la desesperación tranquila de un viejo que morirá ahí dentro. Pero justamente resisto y sé que moriré en la esperanza, pero esta esperanza hay que fundarla.

Hay que intentar explicar por qué el mundo de ahora, que es horrible, es sólo un momento en el largo desarrollo histórico, que la esperanza ha sido siempre una de las fuerzas dominantes de las revoluciones y de las insurrecciones, y explicar cómo siento todavía la esperanza como mi concepción del porvenir.
\end{abstract}

Jean-Paul Sartre (2006, p. 79)

En tiempos en que se anuncia el "fin de los derechos humanos" (Hopgood, 2013) como “última utopía” de Occidente (Moyn, 2010), es oportuno pensar vías alternativas a los derechos humanos o de los derechos humanos. Para ello, sin optimismo ni pesimismo, debemos partir de un hecho: los derechos humanos son un gran logro histórico, pero han sido, también, parte del problema (Kennedy, 2012).

A partir del pensamiento de Jean-Paul Sartre, es posible plantear, como alternativa crítica y contrahegemónica, una lectura de los derechos humanos que reconozca, como presupuesto fundamental, la libertad y la facticidad del hombre en situación. De este modo, si los derechos humanos se conciben como atributos que se radican en un sujeto de derecho, de lo que aquí se trata es de reivindicar, por el contrario, al sujeto de hecho.

Esta empresa la desarrollaré atendiendo el siguiente orden. En un primer momento trataré de despejar las interpretaciones equivocadas, descontextualizadas o incompletas que se han hecho de la obra de Jean-Paul Sartre y que han servido, paradojalmente, para fundamentar una idea de derechos humanos que el pensador francés no planteó ni dio pie a su planteamiento. En segundo lugar, procuraré fundamentar una crítica al concepto estándar de los derechos humanos, evidenciando así las falsas premisas en que éste se apoya y los cinismos que lo caracterizan. Posteriormente, defenderé una visión alternativa y contrahegemónica de los derechos humanos que rescate al sujeto de hecho, al hombre en situación. De esta manera, los derechos humanos deben ser entendidos como llamados fácticos y concretos de una libertad en situación, contingente y proyectada, responsable y comprometida, que ayuda o se dona a otra. Finalmente, enunciaremos algunas consideraciones que, a manera de conclusión, pretenden dar continuidad al debate que insiste en la necesidad de repensar los derechos humanos a la luz de nuevas categorías conceptuales. 
En términos metodológicos, aquí se presenta el resultado de una investigación cualitativa. Se emplea la hermenéutica (Heidegger, 1999, p. 33) como método general de la investigación. Para ello se realiza un análisis de carácter teórico-documental. Entre otras obras del pensamiento sartriano, el estudio se centra en las siguientes: La trascendencia del ego (1968), El ser y la nada (1993), El existencialismo es un humanismo (2009), Crítica de la razón dialéctica (1963), Alrededor del 68 (1973) y, con especial mención, Cahiers pour une morale (1983a).

Conciliar los derechos humanos con la libertad y la facticidad del hombre en situación es en suma, el propósito de este escrito.

\section{SARTRE Y LOS DERECHOS HUMANOS: DESPEJANDO ALGUNOS (NO POCOS) MALOS ENTENDIDOS.}

Salvo contadas excepciones (Poulantzas, 1965a, 1965b; Spademan, 1996; Almeida, 2011; Kail, 2013), los intentos por teorizar el derecho a partir de la filosofía de Jean-Paul Sartre no han estado exentos de malos entendidos ${ }^{1}$. Algunos juristas frecuentan dos lugares comunes que se reproducen como críticas infundadas: (i.) el existencialismo sartriano es una filosofía pesimista (Picado Sotela, 1965) y (ii.) profundamente subjetivista (Gómez Duque, 1980, p. 21; Kaufmann, 1999, p. 320; Kaufmann \& Hassemer, 1992, p. 41; Pacheco G, 1990, p. 35). Algunas de estas acusaciones se apoyan en lecturas incompletas de la obra sartriana e ignoran, además, las defensas que el propio Sartre emprendió de cara a señalamientos de este tipo.

Pues bien, no es mi intención defender lo que Sartre, con holgura, supo hacer. No obstante, y teniendo en cuenta que el tema que aquí me ocupa es, particularmente, el de los derechos humanos, sí quisiera aclarar un mal entendido a este respecto. El mal entendido se suscita con la obra del jurista Bruno Romano $(2010)^{2}$, quien interpreta en Sartre y, específicamente, en La trascendencia del Ego $(1968)^{3}$, un correlato de la propuesta teórica de

\footnotetext{
${ }^{1}$ Sobre el concepto de derecho puede consultarse el texto del profesor Henry Solano Vélez (2016), quien se encarga de dilucidar los diferentes sentidos de esta expresión, despejando sus equívocos. En particular, un análisis referido al concepto de derecho, en la filosofía de Jean Paul Sartre, puede verse en un texto de mi autoría (Arrieta Burgos, 2015), al cual, en todo lo pertinente, me remito.

${ }^{2}$ El texto original en italiano es: Diritti dell'uomo e diritti fondamentali. Vie alternative. Buber e Sartre (Romano, 2009).

3 Publicada en 1936, La transcendance de l'Ego define, según Deleuze y Badiou, un punto de inflexión en la filosofía francesa del siglo XX. La idea de un campo trascendental impersonal, sin identidad subjetiva, que coloca al sujeto constituido en un afuera, es de vital importancia para la filosofía francesa de la
} 
DERECHOS HUMANOS, LIBERTAD Y FACTICIDAD: UNA LECTURA ALTERNATIVA DESDE EL PENSAMIENTO SARTRIANO

ENÁN ARRIETA BURGOS

Kelsen y Luhmann con relación al hombre y sus derechos. Romano (2010) sustenta su teoría a partir de una diferencia entre los derechos del hombre y los derechos fundamentales. Así, teniendo como referente a Martin Buber, el pensador italiano concluye que los derechos del hombre son aquellos inherentes al yo de la persona humana, fuente previa de cualquier imputación, derechos anteriores y connaturales que, a fin de cuentas, desarrollan un contenido material de justicia (p. 92). Por su parte, los derechos fundamentales responden a un fenómeno de positivización que reduce los derechos del hombre a una ley fundamental, útil para el funcionamiento de las operaciones sistémico funcionales (p. 102). Son, de esta suerte, derechos fundamentales de un sujeto sin yo, esto es, meros “utensilios normativos” (p. 229).

A juicio de Romano, el sujeto sin yo es una construcción teórica que encuentra sus raíces en autores como Nietzsche, Husserl, Sartre, Kelsen y Luhmann (Romano, 2010, p. 278). Asumir que la fenomenología, el existencialismo, el positivismo jurídico y el funcionalismo sistémico dan cuenta de una misma orientación teórica es, francamente, una simplificación excesiva. Es cierto, Sartre no afirmaría la existencia de un yo por fuera de toda contingencia, pilar, según Romano, de los derechos del hombre. Pero el pensador francés tampoco defiende, como sugiere Romano, la idea de un sujeto sin yo, impersonal, irresponsable, fatalmente determinado, elemento característico del "nihilismo jurídico" (p. 209).

Desde mi punto de vista, Sartre no afirma que el yo carezca de existencia, asegura, sí, que no tiene sentido hablar de un yo puro como fundamento previo de la conciencia. El yo existe y es trascendente a la conciencia, pero no como un yo puro, sino como un yo fenoménico, empírico, afuera, en el mundo, es decir, como un yo responsable de sí mismo, de los otros y de las cosas. Así, valga decirlo, tampoco es cierto, como sugiere Romano, que en la filosofía de Husserl se niegue, de manera absoluta, la presencia de un yo puro trascendental ${ }^{4}$. $Y$, de igual modo, sostener que La trascendencia del ego (1968) justifica la existencia de "un sujeto sin yo, un ente básico para el funcionamiento del mercado, que utiliza y se vale del derecho como su aparato instrumental" (Romano, 2010, p. 155), me parece exagerado.

segunda mitad del siglo pasado. Sólo a partir de este campo puede entenderse la noción de acontecimiento en Badiou. Ahora bien, a juicio de Deleuze y Badiou, Sartre se queda corto en su intención. La unificación del campo trascendental impersonal en la conciencia de sí le niega al sujeto el más puro afuera (Badiou, 2008, p. 423).

${ }^{4}$ Habría que salir, igualmente, en defensa de Husserl. El filósofo alemán no siempre se opuso a la idea de un yo trascendental, puro y fundamento previo a la conciencia. A partir de 1913, en la segunda edición Investigaciones lógicas (Husserl, 1999, p. 30), al igual que en Ideas I (Husserl, 1962, p. 132) y en la cuarta de las Meditaciones cartesianas (Husserl, 1996, p. 119), Husserl reconocería la existencia de un yo necesario, polo idéntico, constante y concerniente a todas las vivencias, trascendente en la inmanencia.

Revista Eletrônica do Curso de Direito da UFSM www.ufsm.br/redevistadireito v. 11, n. 1 / 2016 
No podemos olvidar que los problemas filosóficos emergen en una tradición de pensamiento. A comienzos del siglo XX, en la primera edición de Investigaciones lógicas ${ }^{5}$, Husserl afirmaba que no le era admisible ni necesaria la concepción de un yo puro, primitivo, unificador, trascendente, fundamento o estructura previa de la conciencia. En el debate vigente para la época, Paul Natorp se valía del término “conciencialidad” para indicar que la conciencia implicaba siempre la relación con un yo. Para Natorp, la idea de una conciencia asubjetiva o impersonal era un contrasentido ${ }^{6}$. Husserl, sin embargo, no estaba de acuerdo con esta posición. Para Husserl, el simple intento de corroborar este "hecho básico" convertía a la conciencia y al yo en “objetos” de comprobación. Por lo anterior, en la primera edición de Investigaciones lógicas, reconoce: "Ahora tengo que confesar que decididamente no puedo encontrar ese yo primitivo como centro necesario de referencia" (Husserl, 1984, p. 374) ${ }^{7}$. Como veremos, ésta es la tesis que Sartre retoma en La trascendencia del Ego (1968).

En el marco de esta discusión, habría que entender que La trascendencia del Ego (1968) es un texto tributario de la primera fenomenología husserliana. Al igual que Husserl, Sartre niega la existencia de un yo puro como fundamento trascendental de la conciencia: “Quisiéramos mostrar aquí que el Ego no está ni formal ni materialmente en la conciencia: está afuera, en el mundo, es un ser en el mundo, como el Ego del otro" (Sartre, 1968, p. 11). El yo, por tanto, tiene una existencia empírica, la cual debe ser sometida, de golpe, como objeto trascendente, a la énoxń fenomenológica (p. 17).

En efecto, la fenomenología no tiene necesidad de afirmar un yo puro domiciliado en la conciencia. La conciencia se define por su intencionalidad, por la cual se trasciende a sí misma y se unifica escapándose (Sartre, 1968, p. 18) ${ }^{8}$. Es la conciencia, siempre individual, la que se unifica a sí misma en el tiempo (p. 19). De este modo, el yo trascendental es un concepto inútil, y lo que comprendemos por tal es, más bien, una expresión de la conciencia, mas no su

\footnotetext{
${ }^{5}$ La primera edición de Investigaciones lógicas carece de traducción al castellano. Inicialmente tuve acceso a una traducción inédita a cargo del profesor Miguel García-Baró. Ahora sigo de cerca una traducción propia a partir de la edición crítica, en alemán, de las obras de Husserl.

${ }_{7}^{6}$ Cf. Vera González (2010. pp. 231 y ss).

${ }^{7}$ Cf. "El yo, en el sentido ordinario del discurso, es un objeto empírico, tanto lo es el yo propio como el ajeno, y cualquier yo es igual que cualquier cosa física, como una casa, un árbol, etc" (Husserl, 1984, p. 363).

8 Sartre necesitaba de una conciencia asubjetiva, desprovista de cualquier materialidad o sustrato subjetivo para afirmar la aparición de la nada en el ser-para-sí de la conciencia. La piedra de toque de la fenomenología sartriana sería la radicalización ontológica del concepto husserliano de intencionalidad: "Toda conciencia, como lo ha demostrado Husserl, es conciencia de algo. Esto significa que no hay conciencia que no sea posición de un objeto trascendente, o, si se prefiere, que la conciencia no tiene contenido" (Sartre, 1993, p. 21).
} 
DERECHOS HUMANOS, LIBERTAD Y FACTICIDAD: UNA LECTURA ALTERNATIVA DESDE EL PENSAMIENTO SARTRIANO

ENÁN ARRIETA BURGOS

condición previa (p. 20). Afirmar la existencia de un yo puro sería tanto como ignorar el carácter irreflexivo de la conciencia (conciencia de primer grado) e introducir en ella un lunar opaco que desdibuja su traslucidez (p. 21), con lo cual, según Sartre, retornamos a la mónada. Todas éstas son, a juicio del filósofo francés, consideraciones metafísicas ajenas a la fenomenología (p. 29).

Ahora bien, si el yo no fundamenta la conciencia (p. 69), “todo está fuera, todo, inclusive nosotros mismos: fuera, en el mundo, entre los demás (Sartre, 1960, p. 28). De este modo, la conciencia se da como una "espontaneidad individuada e impersonal" (Sartre, 1968, p. 73), lo cual significa que, en cada instante, se pone a prueba un ejercicio de libertad que se nos revela como una creación ex nihilo, sin justificación alguna. Una vez desterrado el yo puro de la conciencia, el yo fenoménico se hace un existente comprometido con el mundo. El mundo y el yo se encuentran vinculados en la conciencia absoluta e impersonal, condición primera y fuente de toda existencia (p. 80). Purificada, la conciencia arroja al yo en los contenidos del mundo. Las ideas de moral, derecho y política quedan, de esta manera, fenomenológicamente cimentadas sobre la base de un sujeto de hecho responsable de sí mismo, del mundo y de los otros.

Con estas claridades, puede despejarse el malentendido que a mi modo de ver está presente en la lectura que Romano hace de Sartre. Cuando Sartre defiende la existencia de un yo fenoménico, empírico, situado en el mundo, no pretende, como sugiere el jurista italiano, defender la idea de un yo irresponsable, espectador, indiferente a la alteridad y fatalmente determinado por las leyes causales (Romano, 2010, pp. 157, 178, 228, 230, 231, 236; 245, 249). Sartre tampoco pretendía fundamentar, como insinúa Romano (2010, p. 166), una concepción sistemático funcional de la sociedad ${ }^{9}$. De hecho, un sujeto funcional, irresponsable, espectador, indiferente y fatalmente determinado, como Romano parece leerlo en Sartre (2010, p. 237), es un planteamiento que no tiene cabida en el pensamiento del filósofo francés. Por el contrario, en El existencialismo es un humanismo (2009) Sartre sostiene: “Estamos solos, sin excusas" (Sartre, 2009, p. 42), de allí que la responsabilidad del hombre esté siempre fuera de toda duda. El hombre es siempre responsable (Sartre, 1963a, p. 180), ante sí, frente a todos y por todos (Ramírez, 2014, p. 19).

\footnotetext{
${ }^{9}$ En la tesis de Romano: “La llegada de la máquina simboliza el tránsito de la relación dialógica (Buber) a las relaciones determinadas por las urgencias del mundo (Sartre); consiste por tanto en la transformación de la consciencia de un yo, titular de los derechos del hombre, en una conciencia sin yo, espacio de los derechos fundamentales, positivizados" (2010, p. 291). Así, "La funcionalidad de las cosas invade al hombre y lo transforma en una prótesis impersonal, al cancelar el sentido existencia del derecho" (p. 296). En otro lugar afirmará: "La Máquina hace posible el dominio del yo sin yo, presentado por Sartre" (p. 305).
}

Revista Eletrônica do Curso de Direito da UFSM www.ufsm.br/redevistadireito v. 11, n. 1 / 2016 
En síntesis, nada nos permite concluir que Sartre sea el fundamento de una teoría de los derechos humanos entendidos como derechos fundamentales positivizados en una sociedad funcionalmente diferenciada (Romano, 2010, p. 212). Habiendo despejado este malentendido se hace más fácil comprender la crítica que Sartre formula al concepto estándar de los derechos humanos. Así, el terreno queda abonado para elaborar una propuesta alternativa a este respecto, una propuesta que se dirija desde y hacia el reconocimiento de la libertad y la facticidad del ser humano en situación.

\section{LOS DERECHOS HUMANOS EN CUESTIÓN}

En este capítulo cuestionaré algunas características asociadas a la concepción estándar de los derechos humanos. Es mi deber señalar que Sartre apoya su crítica en el pensamiento de Marx, pero no se limita a él. En efecto, tanto en Marx como en Sartre, los derechos humanos son los derechos que se auto atribuye el hombre burgués, quien "vive al margen del hombre y de la comunidad" (Marx, 1982, p. 478). Sin embargo, la crítica sartriana no se agota en el marxismo, puesto que en ella, adicionalmente, está presente la tradición fenomenológica de nuestro autor. Siguiendo a Boaventura de Sousa Santos (2014, p. 24), es preciso darnos a la tarea hermenéutica de sospechar de los derechos humanos. Sea ésta una oportunidad para ello.

\section{1. ¿El ser humano y la humanidad?}

En su concepción estándar ${ }^{10}$, los derechos humanos se conciben como aquellos derechos inherentes a la persona humana. Se afirma con frecuencia que su violación constituye, además de una vulneración que afecta un derecho subjetivo, un atentado en contra de la conciencia de la humanidad. Estas ideas remiten a dos realidades ahistóricas que constituyen el soporte "humanista" de los derechos humanos: el ser humano y la humanidad. De este modo, el error de la concepción estándar de los derechos humanos ha sido tomar la humanidad como objeto

\footnotetext{
${ }^{10}$ Quisiera recalcar que la crítica se dirige hacia la concepción estándar de los derechos humanos, y no, por ejemplo, respecto de concepciones alternativas, multiculturales y diversas. Una propuesta valiosa puede leerse en numerosos trabajos de Boaventura de Sousa Santos (2002; 2014).
}

Revista Eletrônica do Curso de Direito da UFSM www.ufsm.br/redevistadireito v. 11, n. 1/2016 
natural previo al hombre ${ }^{11} \mathrm{y}$, de paso, al hombre como objeto justificado y, pese a ello, absoluto.

En primer lugar, es necesario reemplazar la pseudo-objetividad del concepto de humanidad por una verdadera subjetividad colectiva, por una totalidad destotalizada en la cual el ser humano se conciba como un uno inunificable (Sartre, 1983a, p. 22) ${ }^{12}$. Esta humanidad, entendida como subjetividad colectiva y no como objetividad hipostasiada, es una meta histórica construible, cuya existencia no deberíamos dar por hecho so pretexto de justificar, en términos ideales, los derechos humanos. En una palabra, "la humanidad no es justificante ni justificable" (p. 78).

En consecuencia, mientras el hombre no sea capaz de construir socialmente la humanidad, no podemos atribuirle valor práctico a un concepto que carece de correlato fáctico. No se trata de desconocer el vínculo existente entre los derechos humanos y la humanidad. Por el contrario, reconociendo la humanidad concreta y contextualizada como fundamento de todo derecho (Pérez Luño, 1987, p. 53), mi propuesta se orienta a edificar una visión alternativa de los derechos humanos, parafraseando a Nietzsche (1996), como hechos humanos, demasiado humanos.

Pero no sólo la idea de humanidad merece reparos. El hombre, tal y como es asumido en la concepción estándar de los derechos humanos, amerita una revisión crítica. Recordemos que el hombre, en la filosofía existencialista, es contingencia y proyecto (Sartre, 1983a, p. 22), facticidad y libertad (p. 277). El ser humano, contingente, vive sin causa y sin razón: "el hombre es una pasión inútil”, afirmará Sartre (1993, p. 637). En tanto que proyecto, el hombre está arrojado hacia un futuro que lo interpela "como fundamento injustificable de toda justificación" (p. 22).

Pues bien, digamos, por lo pronto, que en la concepción estándar de los derechos humanos se pierde de vista el carácter contingente y proyectado de la vida humana. El hombre, como "sujeto de derecho", no es más que un caparazón de objetividad (p. 30). El sujeto provisto de un yo, el hombre de los derechos humanos, es un ser absoluto, formal, dotado de sentido y fundamento. En términos paradójicos, es un ser cuya existencia se justifica en un deber ser. El

\footnotetext{
${ }^{11}$ Kant afirma, con relación a la humanidad del hombre, la existencia de un "algo": "Pues hay algo en nosotros que nunca nos cansamos de admirar una vez que lo reparamos, y es lo que al mismo tiempo eleva a la Humanidad, en la idea, a una dignidad que nunca se sospecharía en el hombre en cuanto objeto de la experiencia" (Kant, 2004, p. 81).

12 Refiriéndose a los derechos humanos, sostiene Marx, en términos similares: "Muy lejos de concebir al hombre como ser genérico, estos derechos hacen, por el contrario, de la sociedad un marco externo a los individuos, una limitación impuesta a su independencia originaria” (Marx, 1982, p. 480).
} 
deber ser, sin embargo, es un sistema normativo de reconocimiento previo: los derechos humanos. Luego, el hombre de los derechos humanos vive porque tiene derechos, mas no porque esté vivo. En esta concepción estándar, es el hombre quien justifica su propia existencia en los derechos humanos, y no los derechos humanos en el hombre. Por ello, para ser exactos, tendría que decirse que es el hombre el inherente a los derechos humanos, y no al revés. Sartre lo expresa de este modo: “La comprensión del hombre como concepto universal y absoluto, propia de los derechos humanos, nos lleva a una contradicción: "yo soy entonces reconocido por el hombre. Pero el hombre soy yo" (Sartre, 1983a, p. 77).

Por esta razón, Sartre defiende una idea controversial: es preciso vivir sin derechos, esto es, hay que perder toda esperanza de justificarse en algo ajeno a la propia existencia (Sartre, 1983a, p. 22). Es éste un presupuesto básico para cualquier comprensión realmente alternativa y contrahegemónica de los derechos humanos. En consecuencia, en su concepción estándar, los derechos humanos se erigen, de un lado, como fundamento justificante (la humanidad) y, de otra parte, como fundamento justificado (el hombre). Ello pone de presente la pregunta por el fundamento mismo de los derechos humanos o, si se quiere, la pregunta por el fundamento del fundamento. Es lo que veremos a continuación.

\subsection{El fundamento místico de los derechos humanos.}

Las leyes, afirmaba Montaigne (2009, p. 356), se mantienen en vigor no porque sean justas, sino porque son leyes, en esto consiste el fundamento místico de su autoridad y aquello que les confiere ventaja ${ }^{13}$. Retomando esta idea, Derrida (1994) señala que el fundamento místico de la autoridad se relaciona con los límites discursivos del propio discurso, esto es, con su potencial performativo. Para Derrida (1994), lo místico refiere "un silencio encerrado en la estructura violenta del acto fundador" (p. 33). Este misticismo se expresa en un famoso adagio: “dura lex, sed lex".

Así las cosas, la concepción estándar de los derechos humanos se vale de un fundamento místico que no se sitúa en la praxis histórica del hombre, sino, por el contrario, más allá de ésta, como elemento intrínseco a los derechos humanos. Por ello, la existencia de hecho del hombre pasa a ser concebida, en los derechos humanos, como una existencia de derecho. La exigencia

\footnotetext{
${ }^{13}$ En contravía de Montaigne, Pascal no reconocería en las leyes ningún tipo de fundamento místico. Para Pascal (1963, p. 507), el fundamento de las leyes era la costumbre. Se trata, si se quiere, de un fundamento sin misterio. En la historia del derecho triunfó la opinión de Montaigne sobre la de Pascal.
} 
de que el hombre sea reconocido como un fin en sí mismo, elemento clave en la concepción estándar de los derechos humanos, supone del reconocimiento, no una realidad, sino un derecho de ser. El fin y el deber ser niegan la facticidad y constituyen el fundamento del antiguo derecho divino (Sartre, 1983a, p. 103) ${ }^{14}$. Así pues, el fundamento místico de los derechos humanos, que se sitúa más allá del hombre, en el deber ser, conlleva la exigencia de que todo hombre sea reconocido como un fin en sí mismo. Esta idea es propia de una moral mediocre y esclavista, basada en una indigna concepción de la dignidad humana.

\subsection{La moral de los derechos humanos.}

Ante la imposibilidad real de contar con un sistema jurídico para la protección universal de los derechos humanos, algunos autores conciben estos derechos, inicialmente, como categorías morales (Laporta, 1987, p. 33) ${ }^{15}$. A mi modo de ver, la relación entre derecho y moral no puede seguirse planteando en términos dicotómicos, sino, más bien complementarios. No en vano, desde un punto de vista histórico, resulta innegable que el sujeto de la moral se ha convertido, hoy por hoy, en "el puro juego formal de relaciones entre personas jurídicas" (Sartre, 1983a, p. 110) ${ }^{16}$. En este sentido, Sartre afirma que el derecho y la moral, en la sociedad burguesa, se corresponden con exigencias abstractas que consideran al hombre como un sujeto de derecho al margen de sus circunstancias concretas (p. 173). Si ello es así, cualquier análisis sobre los derechos humanos remite, en últimas, al discurso moral. Pero una moral abstracta y universal es, en opinión de nuestro autor, una moral mediocre y esclavista.

Para Sartre (1983a, p. 24), la moral abstracta y universal, la moral de la "bonne conscience", la moral de los derechos humanos exige de nosotros un comportamiento moral incluso en situaciones forzosamente inmorales. Es por esta razón que la moral de la mediocridad le permite al opresor tratar al oprimido como una persona abstracta, como un sujeto de derecho

\footnotetext{
${ }^{14}$ Desde la perspectiva sartriana sería posible identificar una relación histórica entre el derecho y la religión, puesto que la religión, "como estructura universal de la realidad humana, es la operación que presenta al ser como ser habido por una estructura íntima: el deber ser" (Sartre, 1983a, p. 154).

${ }^{15} \mathrm{El}$ problema, sin embargo, no se soluciona. Una posición de este tipo afirma una premisa que, desde luego, tampoco podría darse por sentada: la existencia de una moral universal y por ello mismo abstracta, en oposición a los siempre particulares sistemas jurídicos.

${ }^{16}$ Para resumir, con independencia de los ecos que produce esta importante discusión, asumamos, como sostiene Pérez Luño (1987, p. 52), que los derechos humanos responden a instancias o valores éticos anteriores al derecho positivo. Yo agregaría, anteriores, aunque no por ello superiores. Porque, con independencia del debate entre iusnaturalistas e iuspositivistas, ya hemos visto cómo los derechos humanos, en su versión estándar, poseen un fundamento místico ahistórico.
} 
y, al mismo tiempo, de hecho, como objeto de producción y consumo (p. 150). Ahora bien, el reconocimiento del hombre como sujeto de derecho comporta, realmente, la esclavitud. El único derecho del esclavo es el de obedecer. En el fondo, ello pone de presente que todo derecho está fundado en un deber $\mathrm{y}$, a la inversa, que todo deber está fundado en un derecho:

\begin{abstract}
Las instituciones, de otra parte, constituyen determinados grupos sociales como sujetos de derecho. El derecho es otro aspecto de la norma, ya que él se define como un poder sobre los demás, limitado, temporal o permanente, pero incondicional. El imperativo dice: tú debes, el derecho: tú puedes -pero, de hecho, en ambos casos, la ley confiere un poder. Directamente, si se trata del derecho, indirectamente se trata del deber (es el "tu dois donc tu peux" de Kant). Que ese poder sea el mismo en uno y otro caso, es lo que muestra bien la máxima puritana: "Sólo tengo el derecho de cumplir mi deber", que bien podemos invertir en: "no hay deber que no esté fundado en un derecho" (Sartre, 2005a, p. 302).
\end{abstract}

De allí que sin importar el contexto inmoral de opresión de que se trate, toda reclamación de derechos, por parte del oprimido, deba ser catalogada como inmoral, en tanto que supone un incumplimiento al derecho/deber de obedecer.

Por otro lado, la moral abstracta de los derechos humanos es una moral mediocre. En ella, sostiene Sartre (1983a), "el hombre medio es abstraído y sometido a leyes abstractas" (p. 26). Así, la moral del hombre-medio, del hombre promedio, del hombre función ${ }^{17}$, del hombre estadística, en resumen, la moral de "l'homme-fusée" (p. 25), es la moral de la mediocridad. Es una moral y a la vez un sistema jurídico que precisan de un hombre perdido entre medios, solidificado como un medio más, un individuo que pretende ser como todo el mundo ${ }^{18}$, que no se siente destinado ni comprometido con nada, en últimas, un individuo que hace de su vida una comedia (p. 25).

Sin embargo, este hombre no es, a pesar de su mediocridad, un ser resignado. Más bien, aquello que lo caracteriza es la pedantería. Ésta le impide hacerle frente a lo verdaderamente esencial. Es un ser que se vanagloria en los medios preparativos y formales de un fin que ignora, de un fin que, a lo sumo, deviene en mera ilusión o idea reguladora (p. 25). Y cabe preguntarse aquí, ¿no son los derechos humanos, en muchos casos, simples ideas reguladoras? En una bella metáfora, Sartre sostiene lo siguiente: si el hombre medio fuese pintor, lo esencial para él sería

\footnotetext{
${ }^{17}$ Ejemplificando, Sartre afirma cómo el magistrado, en tanto que hombre medio, deviene él mismo en medio de la justicia, de modo que lo único que le preocupa es conseguir los medios para ser un hombre medio (Sartre, 1983a, p. 107).

${ }^{18}$ No se trata de un hombre que pretenda ser igual a todo el mundo, sino como todo el mundo. El matiz es importante, puesto que en él se esconde una falsa conciencia de igualdad.
} 
el pincel y no la obra de arte (p. 25). Valiéndome de esta metáfora, podría decirse que, si el hombre medio fuese abogado, lo esencial para él sería la norma jurídica que consagra el derecho a la vida, y no el estar vivo.

Pero el hombre medio es, también, un hombre de término medio. Le interesan, en consecuencia, las cualidades estéticas medias: la docilidad, la discreción (p. 25), la mesura y el control. Nada en exceso conviene, para confirmar así la estadística. Es un ser del azar, sin compromiso ni destino que forjar. Reconoce, desde luego, la existencia de términos extremos, pero creyéndose síntesis de ellos, sólo son, para él, medios para convertirse en hombre medio (p. 26). De esta suerte, todo pasa a ser inesencial para el hombre mediocre, incluso el mundo que lo rodea, que es sólo un instrumento para su satisfacción.

Como medio que es, el hombre deviene en un ser inesencial y justificado. Esta justificación, que es también subordinación, es provista por los derechos humanos que, en tanto fines de una cadena infinita de medios, permanecen inalcanzables como ideas reguladoras. Así, el hombre es un medio para un fin que ni siquiera conoce. Es por esta razón que la moral de la mediocridad se complementa con la moral del esclavo: los subordinados se descubren inesenciales en la medida en que el jefe, los derechos humanos, son esenciales (p. 23). La esencialidad de los derechos humanos y la inesencialidad del hombre en concreto son consecuencias que se desprenden al asumir, de manera hipostasiada, los conceptos de humanidad, hombre y dignidad. De esta manera, los seres humanos se justifican en su tarea o finalidad o, lo que es lo mismo, en su humanidad y dignidad. De igual modo sucede con los esclavos, quienes encuentran en el amo, y no en ellos mismos, su razón de ser. De allí que para Sartre, sin importar de quien provenga, el derecho se encuentra fatalmente viciado por la existencia del esclavo (p. 153). Derecho y esclavitud son términos inseparables.

Sin embargo, aunque parezca contradictorio, el hombre mediocre, el hombre que es medio de un fin absoluto al cual sirve (en nuestro caso, los derechos humanos), se considera a sí mismo como un fin absoluto, y exige, en consecuencia, que todo aquello cuanto lo rodea, incluyendo los demás, se cosifique como medio al servicio de su vida digna (p. 107). Llegamos aquí a un tema de especial interés que apenas he mencionado: la dignidad humana. 


\subsection{La indigna dignidad humana.}

Los derechos humanos se encuentran íntimamente ligados a la dignidad humana (Habermas, 2010). Nuestra idea de dignidad es, fundamentalmente, una herencia kantiana ${ }^{19}$. El hombre, afirma Kant (2007), es un fin final y, por tanto, no requiere de ningún otro fin como condición para su posibilidad, de suerte que toda la naturaleza se encuentra teleológicamente sometida a él, puesto que es él es el más alto fin (pp. 402 - 403). De esta concepción antropológica se sigue fácilmente el concepto kantiano de dignidad humana. El hombre, a diferencia de las cosas (medios), es digno en tanto que, como fin final, posee valor en sí mismo: "aquello que constituye la condición para que algo sea un fin en sí mismo no tiene un valor meramente relativo o precio, sino que tiene un valor interno, es decir, dignidad" (Kant, 2006, p. 122). Es por esto que el imperativo kantiano constituye la base del fundamento moral de los derechos humanos (Carrillo, 2010, p. 105): "obra de tal modo que te relaciones con la humanidad, tanto en tu persona como en la de cualquier otro, siempre como un fin, y nunca sólo como un medio" (Kant, 2006, p. 104) ${ }^{20}$.

Para resumir, no sería exagerado ver en el pensamiento kantiano el principal soporte filosófico de los derechos humanos en su concepción estándar. Como bien puede inferirse, el concepto de dignidad, en Kant, se encuentra marcado por la concepción del hombre como fin independiente o autónomo. Esta noción está fuertemente relacionada con el concepto de libertad. Estamos, pues, en presencia de una dignidad noumenal que descansa en la idea de autonomía de la voluntad. Frente a esta concepción kantiana, la crítica marxista ha insistido en que los derechos humanos, así entendidos, se corresponden con una concepción del hombre en tanto que "mónada que no depende de nadie" (Marx, 1982, p. 479). A mi modo de ver, Sartre aporta nuevos elementos para comprender esta crítica. Veamos.

\footnotetext{
19 Un análisis crítico sobre el concepto de dignidad humana en Kant y su relación con los derechos humanos puede verse en el escrito de Nuria Belloso Martin (2008). Un estudio histórico del concepto de dignidad a lo largo de la filosofía occidental y, en especial, sobre la concepción kantiana de dignidad entendida como valor interno y absoluto, puede consultarse en la tesis doctoral de Antonio Pelé (2006). La crítica sartriana a la filosofía de Kant se ilustra en un texto de Celia Amorós sobre este particular (2005).

${ }^{20}$ La formulación kantiana del imperativo ha dado lugar a un número importante de malos entendidos. En la lectura equivocada que los abogados hacen de Kant, suele afirmarse que el hombre, según Kant, debe ser tratado únicamente como fin en sí mismo. Kant no dice eso. "El nunca sólo" y el "siempre al mismo tiempo" (Kant, 2006, p. 110) son matices necesarios para no incurrir en una interpretación equivocada. A este respecto, el profesor Solano Vélez (2012, pp. 132 - 138) realiza una aclaración pertinente y necesaria.
} 
El hombre en situación, el hombre en su libertad y facticidad, denunciará el filósofo francés, desaparece en la moral kantiana, toda vez que se transforma en una exigencia puramente formal, en una libertad universal, idéntica a todos y para todos (Sartre, 1983a, p. 147). Dicho en otros términos, en la apuesta teórica de Kant, mi relación con el otro se define y está mediada por el reconocimiento formal de su persona universal (humanidad) y, a su vez, la persona universal del otro se reconoce como libertad abstracta en potencia, mas no como libertad concreta en acto (Sartre, 1983a, p. 110). Es por esta razón que la libertad de los derechos humanos (en sentido negativo, abstracto y potencial) es funcional al statu quo, como quiera que vacía de contenido nuestra relación con los otros y con el mundo, de modo que suprime cualquier posibilidad de cambio, traduciendo todo derecho en un deber. La autonomía, en sentido kantiano, da lugar a predicar la existencia de una libertad negativa ${ }^{21}$. De esta manera, cuando reconocemos en el otro su libertad como fin, rechazamos reconocer su libertad como él (p. 280). De allí que en la concepción estándar de los derechos humanos sólo reconocemos al otro en la medida en que nos es inesencial como medio mediado. Por eso, la libertad de los derechos humanos deviene en una libertad pura y abstracta, abstraída de forma egoísta por el otro. Este tipo de libertad, a juicio de Sartre, prolonga la concepción hegeliana del derecho ${ }^{22}$. De allí que la libertad negativa, la libertad que sirve de base al ideario kantiano, sea, propiamente, un ejercicio de violencia.

De esta manera, si concebir al otro como un fin en sí mismo es un ejercicio de violencia que supone su cosificación como medio, los derechos humanos son los derechos de la sociedad burguesa, es decir, de la "sociedad que hace que todo hombre encuentre en los demás, no la realización, sino, por el contrario, la limitación de su libertad” (Marx, 1982, p. 479). Los derechos humanos hacen de la empresa concreta de la libertad una abstracción formal, reconocida y objetivada como tal por los otros ${ }^{23}$. En la tarea de reconocer y ser reconocido como fin en sí mismo, el hombre se vuelve un "cualquiera”, de suerte tal que poco importa su realidad

\footnotetext{
${ }^{21}$ Sobre el derecho de propiedad como forma negativa, dirá Sartre: "noto que el derecho es puramente negativo y se limita a impedir al prójimo destruir o usar lo que es mío" (Sartre, 1993, p. 360). En este misma obra también expresará: "El derecho de propiedad no aparece sino cuando se me disputa mi propiedad; cuando ya, de hecho, en algún sentido dejó de ser mía” (Sartre, 1993, p. 132). En Morale et Histoire (2005a), Sartre se ocupa ampliamente de analizar, en términos éticos, el derecho de propiedad.

${ }^{22}$ Cf. "La necesidad de este Derecho, en base de su abstracción, se limita a la prohibición: no perjudicar la personalidad y lo que le atañe. Por ello sólo son prohibiciones jurídicas y la forma afirmativa de las normas jurídicas debe tomar como base a la prohibición de acuerdo a su contenido último" (Hegel, 1968, p. 68).

${ }^{23}$ En términos más sencillos, el derecho se vanagloria en reconocer en el hombre un sujeto abstracto de derechos y un objeto concreto de explotación (Sartre, 1963a, p. 74).
} 

ALTERNATIVA DESDE EL PENSAMIENTO SARTRIANO

concreta (Sartre, 1983a, p. 148). Esto le permite a los derechos humanos legitimar las injusticias $^{24}$, en tanto que la justicia se concibe, apenas, como una posibilidad formal (p. 149).

De otra parte, si en esta concepción estándar de los derechos humanos la libertad se entiende en sentido negativo y egoísta, el reconocimiento del hombre, como sujeto de derecho, depende de un presupuesto: la reciprocidad contractual o, lo que es lo mismo, la cosificación mutua entre dos sujetos. De esta manera, el reconocimiento recíproco se constituye en un estadio anterior que permite, por tanto, el desconocimiento de aquellos que no son sujetos de derecho en la medida en que su comportamiento no es recíproco (Sartre, 1963b, p. 259). A quien no tributa reconocimiento, tampoco se le debe. Porque, si bien en su formulación los derechos humanos se presentan como un tipo de reconocimiento objetivo, es el reconocimiento recíproco, de naturaleza subjetiva, el que verdaderamente los caracteriza. En este sentido, habría que decir que, en un doble rasero moral y jurídico, los derechos humanos hacen las veces de reconocimiento subjetivo y objetivo, a conveniencia de la situación de que se trate. Así, por ejemplo, las sociedades defensoras de los derechos humanos tiene el derecho a sustraerse del cumplimiento del derecho y, en consecuencia, a emplear al “derecho" en contra de aquellos que no tributan reconocimiento, léase, respecto del enemigo-no-ciudadano-bárbaro.

Sin embargo, para Sartre, el reconocimiento debe darse en un acto gratuito, sin reciprocidad (p. 76). De no ser así, como en efecto sucede, el reconocimiento recíproco termina por ser el fundamento previo de la existencia humana. El hombre se justifica siempre y cuando sea reconocido. $Y$ es justamente el problema del reconocimiento recíproco el que encontramos en la ambigüedad fundacional de los derechos del hombre y del ciudadano (Santos, 2014, p. $29)^{25}$. En términos prácticos, el no ciudadano carece de derechos humanos ${ }^{26}$. La idea es tan

\footnotetext{
${ }^{24}$ Sartre (1983a) ofrece varios ejemplos. En primer lugar, en la democracia, el derecho del ciudadano se reduce a escoger entre un conjunto de candidatos preestablecidos, de modo que la elección "democrática" es, en palabras del francés, como "la elección del cristiano entre el vicio y la virtud" (p. 57). En este sentido, la verdadera libertad de invención, de configuración de la democracia, es propiedad del gobierno, y es por esta razón que el Estado subsiste persiguiendo su propio interés (p. 57). En segundo lugar, "Si todo hombre tiene el derecho de poseer, poco importa lo que el posea. La esfera de conductas particulares, bienes y obras es dejada a la jurisdicción de la religión y de la moral" (p. 149). Otro ejemplo concreto puede verse en la Crítica de la razón dialéctica (Sartre, 1963a, p. 499). En tercer lugar, para Sartre, el derecho que tienen los empleadores de despedir obreros es una forma de actualización del derecho a matar.

25 Según Agamben (1998), las declaraciones fundacionales de los derechos humanos respondían a una particular dimensión biopolítica de la soberanía ligada al binomio nación-nacimiento. Las guerras mundiales del siglo XX demostraron la insuficiencia de este paradigma biopolítico y la desnudez de la vida como nuda vida. De esta suerte, como sugiere Arendt y afirma Agamben (1998), hay que tomarse en serio el hecho de que el ocaso del Estado-nación es, también, el ocaso de los derechos del hombre (pp. 160 171).
}

Revista Eletrônica do Curso de Direito da UFSM www.ufsm.br/redevistadireito v. 11, n. 1 / 2016 
simple como verdadera, al punto que las sociedades civilizadas la aplican con igual rigor en contra de terroristas y migrantes internacionales. Porque, para efectos concretos, la doble moral y la doble juridicidad de los derechos humanos deviene en un trato idéntico y meramente humanitario -no humano, la distinción es necesaria- respecto del no ciudadano. El no ciudadano, a juicio de las sociedades civilizadas, responde a un fenómeno de barbarie. La dicotomía entre civilización y barbarie está dada por la verificación o no del reconocimiento recíproco. En síntesis, los ciudadanos se reconocen como tales, mientras que los bárbaros se desconocen como tales.

Por esta razón, a juicio de Sartre, todo derecho e, incluso, los derechos humanos, constituyen, en su sentido y justicia, un ejercicio de violencia.

\subsection{La violencia de los derechos humanos.}

En su concepción estándar, los derechos humanos protegen al hombre del uso arbitrario de la violencia estatal. Sin embargo, con Sartre podríamos decir que la violencia no encuentra en los derechos humanos un límite, sino, más bien, una posibilidad para su producción y reproducción. No sólo porque en nombre de los derechos humanos se llevan a cabo guerras e invasiones, sino, más que nada, porque en el centro de su concepción encontramos un germen de violencia. El hombre puro, concebido como tal a partir de la idea de dignidad humana, es un hombre que oscila entre la destrucción del mundo y la destrucción del hombre en concreto ( $p$. 185). Protegido en el fondo de un derecho abstracto, el hombre rechaza habitar el mundo junto con los otros (p. 185). Para el hombre puro de los derechos humanos, para ese hombre que ve en los otros una limitación a su libertad y en el mundo un instrumento para su complacencia, nada, excepto él, debería existir ${ }^{27}$. Por esta razón, sostiene Sartre: "el derecho como exigencia absoluta es precisamente destrucción del mundo" (p. 185). El derecho puro y la violencia pura son una misma realidad. En estricto sentido, la violencia es el derecho que se afirma como tal en contra del mundo y de los otros (p. 185). Sartre lo ejemplifica de la siguiente manera. Si yo soy fuerte en mi derecho, rechazo discutir, deliberar o intentar un arreglo, y acudo, en

\footnotetext{
${ }^{26}$ Para Sartre (1983a, p. 77) ser reconocido como ciudadano significa ser reconocido como titular de unos derechos mínimos: consumidor, en tanto que sujeto pasivo de derechos; y trabajador, funcionario o productor, en tanto que sujeto activo. El hombre sólo se reconoce como ciudadano por sus necesidades y funciones, pero no en su singularidad como ser humano.

${ }^{27}$ Este es el problema que subyace a la forma despiadada cómo los seres humanos nos relacionamos con los demás animales y con la naturaleza.
} 
consecuencia, a la fuerza del Estado para que tutele mi interés. Por eso, la fuerza de mi derecho me autoriza a ser violento y a no tomar en consideración ninguna excusa o razón, de modo que, en nombre del deber ser, ejerzo mi derecho destruyendo lo que es.

Ello es así puesto que "toda violencia se presenta como la recuperación del derecho y recíprocamente todo derecho sostenido inexorablemente contiene en su interior un embrión de violencia" (Sartre, 1983a, p. 185) ${ }^{28}$. De allí que en toda confrontación bélica, en toda revolución, en toda acción violenta, siempre está en disputa el derecho a decir que se fue violento en nombre del derecho. En términos absolutos, sostiene Sartre, no hay ni ha habido nunca una violencia que no se corresponda con la afirmación de un derecho (p. 185). Y el derecho y la violencia descansan, cómodamente, en la noción de derechos humanos, puesto que toda violencia se encuentra atrapada en el fin que persigue (p. 187).

El derecho de un hombre de ser reconocido por su prójimo como un fin en sí mismo supone la posibilidad de exigir violentamente dicho reconocimiento, esto es, la posibilidad de exigir el derecho a ejercer la violencia. La violencia es el resultado de la libertad ejercida por el hombre digno de los derechos humanos que se autoafirma en tanto que deber ser (p. 186). La violencia sólo se valora como tal por más y más violencia (p. 185), lo que significa, para nuestro caso, que la libertad violenta sólo puede ser reconocida por otra libertad violenta. He aquí, de nuevo, la libertad negativa de la que hemos hablado y que asume la forma de exigencia. Toda violencia que se ejerza sobre un otro supone, entonces, un reconocimiento previo de su libertad violenta (p. 186). Por tanto, en la concepción estándar de los derechos humanos, el hombre reclama la libertad de destruir al otro en nombre de su propia libertad. Si ello es así, como en efecto lo es, en no pocas ocasiones los abogados actuamos de mala fe, pues creemos en la inocencia del derecho (p. 186), esto es, en que todo acto violento, por ser jurídico, deja de ser violento.

Con estas premisas, que han servido para elaborar una crítica a la concepción estándar de los derechos humanos, conviene ahora exponer los lineamientos de una propuesta alternativa para su entendimiento.

${ }^{28}$ Cf. "La violencia es una metamorfosis del universo, de tal suerte que la violencia deviene en un derecho" (Sartre, 1983a, p. 209). 


\section{DERECHOS HUMANOS, LIBERTAD Y FACTICIDAD.}

Hasta aquí he bosquejado algunas críticas que es posible plantear, desde la perspectiva sartriana, con relación a la concepción estándar de los derechos humanos. No podría terminar un escrito de esta naturaleza sin antes forzar, como es deber de toda teoría crítica, una lectura alternativa y contrahegemónica de los derechos humanos, fundada en el reconocimiento de la complejidad del hombre en situación. Quisiera soportar esta lectura en la ética sartriana. Podría decirse que esta propuesta no es, principalmente, de carácter jurídico, y se estaría en lo cierto. Pero no podría ser de otra manera, al menos no si consideramos que la ética es una condición anterior al derecho (Sartre, 2005a, p. 274) o, incluso, con Lévinas (2006), que es la filosofía primera, por lo cual no sería equivocado sentar las bases de nuestra lectura sobre reflexiones fundamentalmente éticas.

Así las cosas, la propuesta ética de Jean-Paul Sartre echa raíces en la ontología y la historia. La ontologización e historificación de la ética es una clara apuesta del existencialismo. En este sentido, habría que partir de la concepción que el existencialismo adopta del ser humano. El hombre es contingencia y proyecto. En tanto que proyecto:

[...] no somos lo que somos y somos lo que no somos, es decir, somos transcendencia permanente. Somos libertad. Pero como la libertad no la elegimos sino que se da para nosotros como un hecho, somos al mismo tiempo facticidad. Somos «el hecho de tener que escapar del hecho»" (Amorós, 2005, p. 32 ).

En este sentido, libertad y facticidad son dos términos constitutivos de nuestra condición humana. Es esto lo que Sartre sintetiza al afirmar "el hombre está condenado a ser libre" (Sartre, 2009, p. 43). Esta frase, que se repite hasta el cansancio sin meditar, ha sido, frecuentemente, mal interpretada. Al respecto, el filósofo francés aclara:

Qué significa: "estamos condenados a ser libres". Nunca se ha comprendido bien esta idea. Sin embargo, es la base de mi moral. Partamos del hecho que el hombre es-en-el-mundo. Esto quiere decir que es, al mismo tiempo, una facticidad sitiada y un proyecto-superación. En tanto que proyecto, el hombre asume su situación para superarla. Aquí nos acercamos a Hegel y a Marx: aufheben es conservar superando. Toda superación que no conserva es una huida en lo abstracto. Yo no puedo desembarazarme de mi situación de burgués, de judío, etc, más que asumiéndola para cambiarla. E, inversamente, yo no puedo 
mantener ciertos "estados" o "cualidades" que me enorgullecen más que superándolos para mantenerlos, es decir, no por su conservación como tal (virtudes muertas), sino, para hacer de ellos, constantemente, nuevas hipótesis orientadas hacia un nuevo futuro. Yo no conservo eso que yo soy más que por el movimiento a través del cual invento eso que voy a ser, y no supero eso que soy más que conservándolo. Constantemente tengo que darme lo dado, es decir, tomar mis responsabilidades frente a frente. Pero como soy una facticidad sitiada, como solamente puedo actuar existiendo y haciéndome de la misma naturaleza de aquello sobre lo cual actúo -como actúo a través de mi superficie de pasividad-, no sólo estoy constantemente expuesto en el mundo, sino constantemente modificado desde atrás (Sartre, 1983a. p. 447).

Este pasaje, un poco críptico de Cahiers pour une morale (1983a), es de vital importancia para entender a qué hacemos referencia cuando hablamos de libertad y facticidad. Reconocer la complejidad del hombre es, en consecuencia, reconocer la dialéctica entre estos dos términos constitutivos. La libertad es un hecho dado (facto) que, no obstante y por ello mismo, permite trascender lo dado, superándolo como situación. Es cierto, la facticidad, en concreto, condiciona al hombre, pero en modo alguno lo determina, pues, precisamente, en tanto que somos libres, podemos superar la inmediatez de lo dado, transformándolo en situación (Amorós, 2005, p. 33). En resumen, la libertad en su facticidad hace de la facticidad una posibilidad -y no una fatalidad-.

Pues bien, una propuesta verdaderamente alternativa y contrahegemónica de los derechos humanos debe encontrar, en la compleja relación dialéctica entre libertad y facticidad, una forma de conservación-superación de la existencia humana. De esta manera, se evitan concepciones abstractas, formales y negativas de la libertad humana, al tiempo que se reconoce que es el hombre, en situación, el responsable de su proyecto vital. Ni ingenuidades ni fatalidades, es en el quehacerse con las cosas y con los otros que el hombre hace de su vida lo que él es: "el hombre no es nada mas que su proyecto, no existe mas que en la medida en que se realiza; por lo tanto, no es otra cosa que el conjunto de sus actos, nada mas que su vida" (Sartre, 2009, p. 56).

Por esta razón, el ser humano debería sentirse orgulloso porque, gracias a él, el ser existe (Sartre, 1983a, p. 25). Y el orgullo de existir, que debería ser el fundamento de los derechos humanos, se dirige a reconocer la compleja subjetividad, en cuanto tal, del ser humano, y no se erige, por tanto, como una cualidad que puede ser conferida o retirada por la sociedad a título de reconocimiento (p. 25). 


\subsection{Los derechos humanos: un derecho de provisión.}

Mientras se materializa una propuesta verdaderamente alternativa y contrahegemónica de los derechos humanos, es preciso asumir una posición pragmática. De esta manera, si Mariátegui (1937) tiene razón, esto es, si la edad romántica y los tiempos de vivir con dulzura no tienen ya lugar, habitamos, entonces, una época combativa, en la que el hombre de fe, aquel dispuesto a labrarse un mundo mejor, se ve llamado a vivir peligrosamente.

Bajo este horizonte, conviene entender que los derechos humanos son, parafraseando a Descartes $(1902 \text {, p. } 22)^{29}$, un derecho de provisión. De aquí se desprenden, esencialmente, dos perspectivas fácticas de los derechos humanos. En primer lugar, hay que reconocer que los derechos humanos, en su concepción estándar, se corresponden con un régimen jurídico provisional. Es posible, de esta suerte, construir una vía alternativa a ellos o de ellos, en tanto que, como hechos históricas, se encuentran mediados por la praxis humana. En segundo lugar, los derechos humanos son provisiones, herramientas que sirven en las luchas y reclamaciones sociales. Así, podemos echar mano de los derechos humanos para encauzar las reivindicaciones que el hombre orienta para darse de lo dado un futuro mejor.

Una posición pragmática, en este sentido, fue asumida por Sartre. El filósofo francés defendió la idea de una justicia popular y participó activamente en el Tribunal Russell ${ }^{30}$. El fundamento de la justicia popular es el siguiente: "En concreto: si el desarrollo de la historia no es dirigido por el derecho y la moral -que por el contrario son sus productos-, esas dos superestructuras ejercen sobre ese desarrollo una acción de retorno. Eso es lo que permite juzgar a una sociedad en función de criterios que ella misma ha establecido" (Sartre, 1973, p. 24). Luego, los derechos humanos permiten juzgar a una sociedad en función de los criterios, morales y jurídicos, que ella misma ha establecido. De este modo, el derecho y los derechos humanos, en algunos casos, resultan útiles a los intereses populares (p. 73). Sólo desde esta

\footnotetext{
${ }^{29}$ Recordemos que Descartes, antes de llevar la duda metódica hasta sus últimas consecuencias, se propuso una moral de provisión que le permitiera vivir en el entretanto.

30 Este Tribunal se proponía juzgar el comportamiento de las fuerzas armadas norteamericanas y sus aliados en Vietnam, de conformidad con la legislación internacional que tipificaba los crímenes de guerra (Sartre, 1973, pp. 23, 33). Sartre ilustra esta posición cuando diferencia "Hay aspectos profundamente nefastos del capitalismo monopolístico que no son, sin embargo, crímenes en el sentido jurídico del término (...) Pero en la guerra de Vietnam hay actos, hay agentes responsables, hay leyes relacionadas con esos actos. Nuestra posición política no cuenta más que nuestra indignación ética, se trata de enunciar un juicio de derecho" (Sartre, 1973, pp. 68 - 69).
} 

ALTERNATIVA DESDE EL PENSAMIENTO SARTRIANO

ENÁN ARRIETA BURGOS

perspectiva pragmática es posible reconocer, en los derechos humanos, un potencial emancipatorio ${ }^{31}$.

En este orden de ideas, los derechos humanos pueden ser instrumentalizados como una forma de resistencia capaz de despertar a las masas. Ello es así por cuanto, según Sartre, “Hay una moral de las masas, simple y revolucionaria, que, antes de toda educación política, exige que las relaciones entre los hombres sean humanas y condena la explotación y la opresión como acciones radicalmente malas" (Sartre, 1973, p. 71). Para Sartre, la justicia no es un aparato estatal, sino, más bien, un llamado popular: "los jueces existen en todas partes, son los pueblos” (p. 60). Así, la justicia popular, como instrumentalización estratégica de los derechos humanos, da cuenta de una jurisdicción revolucionaria, en donde son las masas las que juzgan y en nombre de quienes se juzga, de modo tal que el juicio, en su objetividad, pertenece sólo a el pueblo (p. 76): “nadie está excusado de ignorar la ley del pueblo” (p. 249), sentencia Sartre.

En consecuencia, desde una perspectiva pragmática, los derechos humanos responden a la necesidad de reconocer que es el hombre en situación, en su libertad y facticidad, el responsable de su futuro individual y colectivo. Los derechos humanos son un derecho de provisión que, no obstante su provisionalidad, provee, para el campo jurídico, herramientas de combate.

\subsection{El llamado de los derechos humanos.}

En la búsqueda de un sujeto de derecho, los derechos humanos pierden de vista al hombre de hecho. En este sentido, Sartre afirma que, si se suprime al esclavo, es decir, si hacemos a un lado el ropaje jurídico, no quedan sino hombres de hecho (Sartre, 1983a, p. 588). Una propuesta alternativa de los derechos humanos, que reconozca la libertad y la facticidad del hombre en situación, supone deconstruir la concepción estándar de los derechos humanos. A lo largo de este escrito he indicado algunas sugerencias en esta orientación. Más que nada, he destacado la necesidad de repensar la humanidad como una construcción subjetiva e histórica, y al hombre como ser contingente y proyectado.

${ }^{31}$ Cf. "Se nos ha reprochado que estamos haciendo legalismo pequeño-burgués. Es verdad y acepto esta objeción. Pero, ¿a quién queremos convencer? ¿A las clases que están en lucha contra el imperialismo, o a ese sector bastante ancho de la clase media que está hoy vacilante? Son a las masas pequeño-burguesas a las que es necesario hoy despertar y sacudir, porque su alianza -incluso en el plano interno- con la clase obrera es deseable. Y es por el legalismo que se les puede abrir los ojos. Por otra parte, tampoco es malo recordar a las clases trabajadoras, que han sido a menudo entrenadas para no considerar más que la eficacia, que hay una estructura ético-jurídica en toda acción histórica"(Sartre, 1973, p. 29). 
Ahora bien, desde la facticidad del hombre concreto, desde el existir en su ocasionalidad (Heidegger, 1999, p. 49), los derechos humanos deben entenderse como un llamado y no como una exigencia. Sólo así es posible fundamentar la universalidad concreta de ese universal singular que es el hombre en su relación con el mundo y con los otros ${ }^{32}$.

La libertad formal de los derechos humanos olvida que la verdadera libertad es "una empresa infinitamente concreta y calificada que es necesario reconocer en su empresa" (Sartre, 1983a, p. 147). El llamado, a diferencia de la exigencia, comienza por admitir que toda libertad es, siempre, una libertad personal en situación (p. 285). Por lo anterior, lejos de totalizar, el llamado supone la diversidad de libertades en situación ${ }^{33}$. No es necesario, por tanto, concebir una libertad de atrás, una libertad fundamento o unificadora, tal y como sucede en la concepción estándar de los derechos humanos.

En su diversidad, es preciso considerar que toda libertad concreta debe ser asumida como tal por las otras libertades, simplemente, porque, en la medida en que es libre, el hombre quiere, desea. Por ello, las relaciones entre libertades concretas no están condicionadas por el reconocimiento recíproco, sino por la ayuda, originalmente gratuita y desinteresada. El reconocimiento unilateral, la donación, implica ayudar al otro a perseguir y a realizar su propio fin, sea cual sea, esto es, a desarrollarse como libertad concreta.

Dicho de otro modo, entendidos desde una dimensión fáctica, los derechos humanos no se basan en un reconocimiento recíproco, sino en una "comprensión preontológica de la libertad del otro por mi libertad (...). El fin del otro no puede aparecérseme como fin más que cuando lo adoptamos como nuestro" (Sartre, 1983a, p. 288). El llamado, en lugar de la exigencia, supone una relación concreta de persona a persona, sin mediación alguna de normas jurídicas o conceptos abstractos. Así, los derechos humanos dejan de concebirse como una relación hombre-humanidad-hombre, para entenderse a partir de la facticidad concreta de cada una de las libertades en situación, esto es, en las relaciones directa entre hombres.

Ello es así porque, a diferencia de la concepción estándar de los derechos humanos, para el existencialismo la alteridad no se concibe como algo externo, sino, por el contrario, como un elemento constitutivo de nuestra propia vida. El otro interesa a nuestro ser "concreta y

\footnotetext{
${ }^{32}$ Cf. “(...) el hombre, singularidad irremediable, es el ser por el que lo universal viene al mundo y por el que el azar constitutivo toma, desde el momento en que es vivido, figura de necesidad. En Kierkegaard aprendemos que lo vivido son los azares no significativos del ser, en cuanto se trascienden hacia un sentido que no tenían al comienzo y al que yo denominaría el universal singular" (Sartre, 2005b, p. 27).

${ }_{33}$ El reconocimiento de la diversidad de libertades en situación permitiría lo que Boaventura de Sousa Santos (2002) denomina "hermenéutica diatópica", es decir, una concepción multicultural de los derechos humanos.
} 
ónticamente en las circunstancias empíricas de nuestra facticidad" (Sartre, 1993, p. 280), de tal manera que "basta que otro me mire para que yo sea lo que soy" (p. 290). Así las cosas, es preciso defender la necesidad de una condición ontológica previa a cualquier reconocimiento recíproco: el orgullo de existir. Antes de negociar con el otro un reconocimiento recíproco, el hombre debería reconocer que él, en su yo, es un otro. Es lo que Sartre resume al concluir, a partir de Rimbaud: "Yo es otro" (Sartre, 1968, p. 73) ${ }^{34}$. El otro nos constituye ontológicamente: "en el fondo los otros son aquello que hay de más importante en nosotros mismos para nuestro propio conocimiento de nosotros mismos" (Sartre, 1979, p. 182). De esta suerte, nuestra relación con la alteridad pasa por una disposición ontológica de negación que emerge en la propia tesitura de nuestra intimidad (Sartre, 1993, p. 258) 35 :

Sin duda, nuestra realidad humana exige ser simultáneamente para-sí y para-otro [...] ocurre -y ello es indubitable- que nuestro ser en relación con su ser-para-sí es también para-otro; el ser que se revela a la conciencia reflexiva es para-sí-paraotro; el cogito cartesiano no hace sino afirmar la verdad absoluta de un hecho: el de mi existencia; del mismo modo, el cogito algo ampliado del que aquí usamos, nos revela como un hecho la existencia del prójimo y mi existencia para otro. Es todo lo que podemos decir" (Sartre, 1993, p. 309 y 310).

Cuando se entiende que el otro nos constituye en nuestra propia subjetividad, se hace innecesario el reconocimiento recíproco. Basta la mirada del otro, su rostro en palabras de Lévinas (2002, p. 207), para que el hombre se sienta llamado, en términos éticos, a la responsabilidad y al compromiso. No se requieren categorías jurídicas para reconocer, de hecho, la condición humana del otro, esto es, mi propia condición.

En conclusión, esta libertad concreta y en situación, empresa personal que es preciso reconocer en tanto empresa, permite superar el individualismo despolitizado que caracteriza la noción estándar de los derechos humanos. Esta libertad calificada por la facticidad se traslapa con la responsabilidad y el compromiso, y es sólo a través de un ejercicio responsable y comprometido con la vida como puede estatuirse, en términos históricos, una verdadera universalidad singular de los derechos humanos.

\footnotetext{
${ }^{34}$ En francés la expresión resulta un poco más sugestiva: “Je est un autre” (Sartre, 1966, p. 78).

${ }^{35} \mathrm{Cf}$. "Triple aspecto del Yo-Otro: $1^{\circ}$ demonio que me posee; $2^{\circ}$ mi propiedad; $3^{\circ}$ mi Destino. Siendo el Otro en mí, él aparece como exigencia y como algo sagrado" (Sartre, 1983a, 423).
} 


\subsection{Responsabilidad y compromiso.}

El llamado afinca sus raíces en una moral concreta y revolucionaria, finita y creadora (Sartre, 1983a, p. 487) que, como teoría de la acción concreta, se concibe, por tanto, como teoría del trabajo y de la lucha (p. 25). De este modo, el fundamento moral de los derechos humanos no debería ser, pues, una moral abstracta, mediocre y esclavista, sino una moral concreta y revolucionaria.

Los derechos humanos, en su versión estándar, operan como categorías que legitiman el comportamiento humano. Sin embargo, como ya vimos, si reconocemos al ser humano en su facticidad, debemos concluir que éste, en tanto libre, es siempre responsable. El hombre es aún más responsable cuando se niega a asumir su responsabilidad, pues actúa de mala fe. Estamos solos y sin excusas, es decir, no hay ningún tipo de esencia que preceda a nuestra existencia (Sartre, 2009, p. 30) o, lo que es lo mismo, lo esencial es la contingencia (Sartre, 1938, p. 184).

Pero el hombre, sin excusas, no sólo es responsable por su propio destino, sino, también, por el de los demás: “no hay ninguno de nuestros actos que, al crear al hombre que queremos ser, no cree al mismo tiempo una imagen del hombre tal como consideramos que debe ser (Sartre, 2009, p. 34). Por ello, elegir hace que todo hombre invente al hombre a cada instante (p. 34). Desde esta perspectiva, la humanidad, como categoría subjetiva e histórica, se construye en cada una de nuestras elecciones. La humanidad, así entendida, deja de concebirse como un particularismo universalizado por Occidente (Santos, 2014, p. 39), deja de hipostasiarse como un ideal impuesto por el discurso de los derechos humanos, y pasa a integrar la trama cotidiana de nuestros actos. Habría, pues, tantas elecciones de humanidad como actos de libertad. En la riqueza del detalle, está sería una invitación a reconocer lo universal (humanidad en lo singular (el hombre en situación) y lo singular en lo universal ${ }^{36}$.

La ontología sartriana de la responsabilidad nos traslada al plano del compromiso ${ }^{37}$. Como refería Simone de Beauvoir: "Para Sartre, la conciencia está comprometida siempre, y es necesariamente finitud; y Sartre sólo se propone actuar como individuo finito, limitado, situado" (De Beauvoir, 1963, p. 102). Comprometerse no es aceptar la vida resignadamente, sino asumir

\footnotetext{
${ }^{36}$ En el ser y la nada, para hacer notar que lo universal no tiene sentido sino a propósito de lo individual, Sartre expresará: "Sin duda, los derechos que reclamo al prójimo ponen la universalidad del sí mismo; la respetabilidad de las personas exige el reconocimiento de mi persona como universal. Pero lo que se vuelca en este ser universal y lo llena es mi ser concreto e individual” (Sartre, 1993, p. 268).

${ }^{37}$ Un estudio sobre el problema del compromiso y la responsabilidad en la filosofía sartriana puede verse en los diferentes trabajos de Olivier D' Jeranian (2013; 2015).
} 
que todo aquello que nos acontece es nuestra responsabilidad (Sartre, 1983b, p. 122). Pensar lo contrario, no asumirnos como responsables, implica hacernos culpables, mas no responsables, de nuestro destino. $Y$ cada situación demanda de nosotros un compromiso concreto. En el caso del escritor y, por qué no, de la academia en general, el compromiso sigue siendo el mismo que Sartre proponía en 1946: "construir una teoría positiva de la libertad y de la liberación” (Sartre, 1999, p. 59). Ojalá el lector puede tomar este escrito como un esfuerzo dirigido a atender este compromiso.

\section{CONCLUSIÓN}

A lo largo de este escrito me he planteado, básicamente, tres propósitos que convergen, todos ellos, en una lectura crítica y alternativa de los derechos humanos a partir del pensamiento sartriano: (i.) despejar algunos malos entendidos respecto de la visión que Sartre ofrece de los derechos humanos; (ii.) plantear una crítica a la concepción estándar de los derechos humanos y; (iii.) esbozar una propuesta alternativa y contrahegemónica de estos.

En primer lugar, queda visto cómo la filosofía sartriana ha sido mal interpretada por quienes ven en ella una postura pesimista y egoísta que da pie a fundamentar la positivización de los derechos humanos como derechos fundamentales. Nada más alejado de la realidad. Es preciso darse a la tarea de continuar despejando estos malos entendidos que olvidan, en últimas, que el existencialismo es, ante todo, un humanismo.

En segundo lugar, he intentado deconstruir los conceptos de humanidad, ser humano, libertad y dignidad que aparecen en la base de la concepción estándar de los derechos humanos. Así, he evidenciado el fundamento místico y la violencia que les subyace. Ahora bien, a efectos de resumir los principales elementos de esta crítica, quisiera aprovechar que ella, en gran medida, se encuentra ilustrada en uno de los primeros textos literarios de nuestro autor: La infancia de un jefe. Lucien Fleurier, el protagonista de esta historia narrativa, al finalizar la obra, después de tomar conciencia acerca de su lugar en el mundo, expresa para sí:

“iTengo derechos!” ¡Derechos! Algo del género de los triángulos y los círculos;
era algo tan perfecto que no existía, se podían trazar millares de redondeles con
el compás, no se llegaría a realizar ni un solo círculo. Del mismo modo,
generaciones de obreros podrían obedecer escrupulosamente las órdenes de
Luciano; no agotarían nunca su derecho a mandar, los derechos estaban más allá
de la existencia, como los objetos matemáticos y los dogmas religiosos. Y he aquí
que Luciano era justamente eso, un enorme racimo de responsabilidades y de

Revista Eletrônica do Curso de Direito da UFSM www.ufsm.br/redevistadireito v. 11, n. 1/ 2016 

ALTERNATIVA DESDE EL PENSAMIENTO SARTRIANO

derechos. Durante largo tiempo había creído que existía por azar, a la deriva: pero se equivocó por haber reflexionado demasiado. Mucho antes de su nacimiento, su lugar estaba ya marcado bajo el sol, en Ferolles. Ya -aún mucho antes del matrimonio de su padre - se le esperaba; si había venido al mundo era para ocupar ese lugar: "Existo, pensó, porque tengo el derecho de existir" (Sartre, 2005c, p. 234).

En la crítica sartriana, los derechos humanos, como los objetos matemáticos o las figuras geométricas, se vanaglorian de su propia perfección y se instalan más allá del mundo del ser, negando la existencia de lo que es. En este sentido, los derechos humanos dan cuenta de una ontología de la destrucción. Pero son, asimismo, instrumentos para la preservación del statu quo, lo cual quiere decir, de una parte, que los oprimidos sólo tienen el derecho/deber de obedecer y, de otro lado, que los opresores tienen el derecho a ordenar o, lo que es lo mismo, a existir. Para resumir, el derecho no es, sino que se tiene. Negando la realidad del ser en nombre del deber ser, los derechos humanos ejercen un tipo de violencia que, usualmente, favorece a los poderosos. Sin embargo, en algunas ocasiones, los derechos humanos pueden ser usados con una finalidad emancipatoria.

En tercer lugar, como es deber de toda propuesta crítica que se traduzca no sólo en una deconstrucción, sino, también, en una reconstrucción, quise esbozar los lineamientos básicos de una propuesta alternativa y contrahegemónica de los derechos humanos. En este sentido y en el entretanto, conviene reconocer que los derechos humanos, en su concepción estándar, son un derecho de provisión con potencialidades emancipatorias. Ahora bien, es preciso migrar hacia una nueva concepción de los derechos humanos que se edifique sobre la base del reconocimiento de la libertad y la facticidad del hombre en situación. En esta nueva mirada, los derechos humanos se conciben como un llamado que presupone la diversidad de cada de una de nuestras opciones vitales y la solidaridad entre ellas. Sólo así es posible construir la humanidad como realidad subjetiva e histórica. La humanidad se entreteje en cada una de nuestras elecciones, a partir de la asunción responsable y comprometida de nuestra existencia, del mundo y de los otros. La base de una propuesta de este tenor ha quedado apenas esbozada y ameritaría desarrollos posteriores que la detallen y amplíen.

En todo caso, retomando el epígrafe con el que se daba inicio a este escrito, bien sea que asistamos o no al ocaso de los derechos humanos, nuestra misión no parece ser distinta a la que Sartre, a pocos días de morir, se proponía: hay que fundar la esperanza ahora. 

ALTERNATIVA DESDE EL PENSAMIENTO SARTRIANO

ENÁN ARRIETA BURGOS

\section{REFERENCIAS}

Almeida, S.L. (2011). Sartre: Direito e Política. Tese de Doutorado. São Paulo: Universidade de São Paulo.

Amorós, C. (2005). Sartre, crítico de Kant. Daimon, 25-40.

Arrieta Burgos, E. (2015). Introducción a la crítica del concepto de derecho en Jean-Paul Sartre. En A. Ruíz, Crisis de la noción de derecho (págs. 85 - 116). Medellín: Editorial Universidad Pontificia Bolivariana.

Badiou, A. (2008). Lógicas de los mundos: El ser y el acontecimiento, 2. Buenos Aires: Manantial. Carrillo Carillo, L. (2010). El concepto kantiano de ciudadanía. Estudios Filosóficos, 103 - 121.

Belloso Martin, N. (2008). El principio de dignidad de la persona humana en la teoría kantiana: algunas contradicciones. En El pensamiento jurídico: pasado, presente y perspectiva: libro homenaje al Prof. Juan José Gil Cremades (págs. 193 - 218). Zaragoza: El Justicia de Aragón.

De Beauvoir, S. (1963). J.P. Sartre versus Merleau-Ponty. (A. LEAL, Trad.). Buenos Aires: Siglo Veinte.

Carrillo Carillo, L. (2010). El concepto kantiano de ciudadanía. Estudios Filosóficos, 103 - 121.

Derrida, J. (1994). Force de Loi. Le Fondement mystique de l'autorité. Paris: Galilée.

Descartes, R. (1902). Oeuvres de Descartes. Discours de la méthode \& essais. VI. (A. Charles, \& P. Tannery, Edits.). Paris: Léopold Cerf.

D'Jeranian, O. (16 de Mayo de 2015). L'ontologie sartrienne de la responsabilité dans L'être et le néant. Recuperado el 23 de Mayo de 2015, de Academia: https://www.academia.edu/12393257/Lontologie_de_la_responsabilité_chez_Jean-Paul_Sartre

D'Jeranian, O. (23 de Abril de 2013). Le problème de l'engagement chez Sartre: itinéraire.

Recuperado el 25 de Mayo de 2016, de Academia:

https://www.academia.edu/9762355/Le_problème_de_lengagement_chez_Sartre_itinéraire_philoso phique

Gómez Duque, L. F. (1980). Filosofía del derecho. Bogotá: Universidad Externado de Colombia.

Habermas, J. (2010). El concepto de dignidad humana y la utopía realista de los derechos humanos. Diánoia, 55 (64), 3 - 25.

Hopgood, S. (2013). The endtimes of human rights. Ithaca: Cornell University Press.

Heidegger, M. (1999). Ontología. Hermenéutica de la facticidad. (J. Aspiunza, Trad.). Madrid: Alianza.

Hegel, G. W. (1968). Filosofía del derecho. (A. Mendoza de Montero, Trad.). Buenos Aires: Claridad.

Husserl, E. (1984). Husserliana-Gesammelte Werke. Band XIX/I. Logische Untersuchungen. Zweiter Teil. Untersuchungen zur Phänomenologie und Theorie der Erkenntnis. Text der I. und der 2. Auflage ergänzt durch. (U. Panzer, Ed.). Dordrecht: Kluwer Academic Publishers. 
DERECHOS HUMANOS, LIBERTAD Y FACTICIDAD: UNA LECTURA ALTERNATIVA DESDE EL PENSAMIENTO SARTRIANO

Husserl, E. (1962). Ideas relativas a una fenomenología pura y una filosofía fenomenológica, Tomo I (2a ed.). (J. Gaos, Trad.). México: Fondo de Cultura Económica.

Husserl, E. (1999). Investigaciones lógicas 1. (M. García Morente, \& J. Gaos, Trads.). Madrid: Alianza.

Husserl, E. (1996). Meditaciones cartesianas. (M. García Morente, \& M. García-Baró, Trads.). México: Fondo de Cultura Económica.

Kail, M. (2013). "Sartre et le question du droit". Annales de l'Université de Craiova. Serie de Philosophie, 32: 15-30.

Kant, I. (2007). Crítica del juicio. (M. García Morente, Trad.). Madrid: Espasa Calpe.

Kant, I. (2004). El conflicto de las facultades. (E. Tabernig, Trad.). Buenos Aires: Losada.

Kant, I. (2006). Fundamentación de la metafísica de las costumbres (17ª ed.). (L. Martínez de Velasco, Trad.). Madrid: Espasa Calpe.

Kaufmann, A. (1999). Filosofía del derecho. (L. Villar Borda, Trad.). Bogotá: Universidad Externado de Colombia.

Kaufmann, A., \& Hassemer, W. (1992). El pensamiento jurídico contemporáneo. (J. A. García Amado, \& M. J. Fariñas Dulce, Trads.). Bogotá: Debate.

Kennedy, D. (2012). The international human rights regime: still part of the problem? En R. Dickinson, E. Katselli, C. Murray, \& O. Pedersen (Eds.), Examining Critical Perspectives on Human Rights (págs. 19-34). Cambridge: Cambridge University Press.

Laporta, F. (1987). Sobre el concepto de derechos humanos. Doxa (4), 22 - 46.

Lévinas, E. (2002). Totalidad e infinito. Ensayo sobre la exterioridad (6a ed.). (D. Guillot, Trad.). Salamanca: Sígueme.

Lévinas, E. (2006). Ética como filosofía primera. A Parte Rei. Revista de Filosofía (43), 11 - 21.

Mariátegui, J. (1937). La emoción de nuestro tiempo. Dos concepciones de la vida. Recuperado el 22 de Mayo de 2016, de www.marxists.org:

https://www.marxists.org/espanol/mariateg/oc/el_alma_matinal/paginas/dos\%20concepciones\%20d e\%20la\%20vida.htm

Marx, K. (1982). Sobre la cuestión judía. En K. Marx, Escritos de juventud (W. Roces, Trad., págs. 461 - 490). México: Fondo de Cultura Económica.

Montaigne, M. d. (2009). Les Essais. Libre III. Traduction en français moderne du text de l' edition de 1595 par Guy de Parnon. Paris: Pernon.

Moyn, S. (2010). The last utopia: human rights in history. Cambridge:: Belknap Press of Harvard University Press. 
Nietzsche, F. (1996). Humano, demasiado humano. Un libro para espíritus libres (Vol. I). (A. Brotons Muñoz, Trad.). Madrid: Akak.

Pacheco G, M. (1990). Teoría del Derecho (Cuarta ed.). Santiago: Editorial Jurídica de Chile.

Pascal, B. (1963). Pensées. En B. Pascal, Oeuvres complètes (págs. 493 - 641). Paris: Éditions du Seuil.

Pelé, A. (Julio de 2006). Tesis doctoral. Filosofía e historia en el fundamento de la dignidad humana. Obtenido de Universidad Carlos III de Madrid:

http://orff.uc3m.es/bitstream/handle/10016/3052/Tesis_Pele.pdf?sequence=7

Pérez Luño, A.-E. (1987). Concepto y concepción de los derechos humanos (Acotaciones a la Ponencia de Francisco Laporta). Doxa (4), 47 - 66.

Picado Sotela, S. (1965). Jean-Paul Sartre: una filosofía de la libertad. Revista de Filosofía de la Universidad de Costa Rica, 301 - 322.

Poulantzas, N. (1965a). Nature des choses et droit. Paris: Librairie Genérle de Droit et de Jurisprudence.

Poulantzas, N. (1965b). "La critique de la raison dialectique de J.-P. Sartre et le Droit". Archives de Philosophie du Droit, 10: 83-106.

Ramírez, C. (2014). El retorno al ser. Una propuesta frente al sinsentido. Medellín: Universidad Pontificia Bolivariana.

Romano, B. (2010). Derechos del hombre y derechos fundamentales. Vías alternativas: Buber y Sartre. (A. Rivera Llano, Trad.). Bogotá: Doctrina y Ley.

Romano, B. (2009). Diritti dell'uomo e diritti fondamentali. Vie alternative. Buber e Sartre. Roma: Giappichelli.

Santos, B. (2014). Derechos humanos, democracia y desarrollo. Bogotá D.C.: Dejusticia.

Santos, B. (2002). Hacia una concepción multicultural de los derechos humanos. El otro derecho (28), $59-83$.

Sartre, J.-P. (1973). Alrededor del 68. Situación ocho. (E. Gudiño Kieffer, Trad.). Buenos Aires: Losada.

Sartre, J.-P. (1983a). Cahiers pour une morale. Paris: Gallimard.

Sartre, J.-P. (1963a). Crítica de la razón dialéctica precedida de cuestiones de método. Tomo I. Teoría de los conjuntos prácticos. Libro I. De la praxis individual a lo práctico inerte. (M. Lamana, Trad.). Buenos Aires: Losada.

Sartre, J.-P. (1963b). Crítica de la razón dialéctica. Tomo I. Teoría de los conjuntos prácticos. Libro II. Del grupo a la historia. (M. Lamana, Trad.). Buenos Aires: Losada. 
Sartre, J.-P. (2009). El existencialismo es un humanismo. (V. Praci de Fernández, Trad.). Barcelona: Edhasa.

Sartre, J.P. (1993). El ser y la nada: Ensayo de ontología fenomenológica. (J. Valmar, Trad.). Buenos Aires: Altaya.

Sartre, J.-P. (2005b). El universal singular. En Sartre, Jean-Paul, G. Marcel, K. Jaspers, E. Paci, E. Lévinas, y otros, Kierkegaard vivo. Una reconsideración (A.-P. Sánchez, Trad., págs. 11-38). Madrid: Ediciones Encuentro.

Sartre, J.-P. (2005c). La infancia de un jefe. En J.-P. Sartre, El muro (G. Urquiza, Trad., págs. 147235). México: Época.

Sartre, J.-P. (2006). La esperanza ahora. (I. Herrera, Trad.). Madrid: Arena Libros.

Sartre, J.-P. (1938). La nausée. Paris: Gallimard.

Sartre, J.-P. (1999). La responsabilité de l'écrivain. Paris: Verdier.

Sartre, J.-P. (1966). La transcendance de l'Ego. Esquisse d'une description phénoménologique. Paris: Vrin.

Sartre, J.-P. (1968). La trascendencia del Ego. (Ó. Masotta, Trad.). Buenos Aires: Calden.

Sartre, J.-P. (1983b). Les carnets de la drôle de guerre. Novembre 1939 - Mars 1940. Paris: Gallimard.

Sartre, J.-P. (2005a). Morale et Histoire. Les Temps Modernes 2005/4 (632-633-634), 268-414.

Sartre, J.-P. (1979). Un teatro de situaciones. (M. Arlt, Trad.). Buenos Aires: Losada.

Sartre, J.-P. (1960). Una idea fundamental de la fenomenología de Husserl: la "intencionalidad". En: El hombre y las cosas (E. Luis, Trad., págs., 26-29). Buenos Aires: Losada.

Spademan, T.B. (1996). Sartre, Marx and legal theory. Doctoral dissertation. Purdue: University of Purdue.

Solano Vélez, H. (2012). Pulimento raciovitalista del concepto de derecho. Medellín: Diké.

Solano Vélez, H. (2016). Introducción al estudio del derecho. Medellín: Universidad Pontificia Bolivariana.

** Artigo convidado pelo Conselho Editorial. 